\title{
Awareness and accessibility of Hepatitis B vaccination among undergraduate clinical students of a tertiary institution in South Eastern Nigeria
}

\author{
Anselem Obioma Inya 1, Onyeka Chukwudalu Ekwebene 1, *, Chukwuanugo N Ogbuagu 2, Chioma Phyllis \\ Nnamani ${ }^{3}$ and Chioma Favour Ekwebene 4 \\ ${ }^{1}$ Nnamdi Azikiwe University Teaching Hospital, Nnewi. \\ ${ }^{2}$ Center for Community Medicine and Primary Health Care, Nnamdi Azikiwe University Teaching Hospital, Nnewi, \\ Nigeria. \\ ${ }^{3}$ Department of Family Medicine, Nnamdi Azikiwe University Teaching Hospital, Nnewi, Anambra State, Nigeria. \\ ${ }^{4}$ College of Nursing, Diocesan Hospital, Amichi, Nigeria.
}

Magna Scientia Advanced Research and Reviews, 2021, 02(02), 070-079

Publication history: Received on 02 June 2021; revised on 08 July 2021; accepted on 11 July 2021

Article DOI: https://doi.org/10.30574/msarr.2021.2.2.0051

\begin{abstract}
Hepatitis B virus Infection is a chronic Infection with increasing incidence and worldwide prevalence. It is a leading cause of liver failure and hepatocellular carcinoma. Healthcare personal, chronic blood transfusion, unprotected sex, etc are some major risk factor of contracting the disease. It can be prevented by vaccination. This study was carried out among undergraduate Clinical students of college of Health Science, Nnamdi Azikiwe University (CHS-NAU), Nnewi it was a cross-sectional descriptive study using the convenience sampling method. Pretested self-administered questionnaires were distributed and the data analyzed using the statistical package for social science (SPSS) Version 20.0. A total of 178 questionnaires were distributed with a response rate of $100 \%$ (178). The study showed a high level of knowledge of HBV vaccination and consider attitude towards the need for vaccination but poor compliance to update due to busy schedule, cost, and level of study. HBV vaccination is low among the students of a CHS-NAU as in other parts of Nigeria and Africa with similar reasons. Good Policy enactment and implementation can help bridge the gap between the awareness, attitude and accessibility of vaccine.
\end{abstract}

Keywords: Hepatitis; Lamuvudine; vaccination; virus

\section{Introduction}

Hepatitis B Virus infection, is a major global problem affecting large number of people every year. Hepatitis B Virus primarily targets the liver and can cause both acute \& chronic liver diseases. HBV infection is asymptomatic in majority of the people and the chronic infection may lead to serious complications such as cirrhosis of the liver, \& hepatocellular carcinoma. As per the Latest World Health Organization (WHO) report dated July 18, 2018; globally by the end of 2015, an estimated 257 million people were living with HBV and approximately 887,000 deaths have occurred mainly because of chronic complications of HBV infection.

HBV infection is an occupational hazard, and the risk of health care workers and clinical medical students getting infected is 2-10times higher than in other general population, medical students must have proper knowledge about HBV infection, modes of transmission, clinical features, complication \& preventive measures. The proper knowledge helps them take necessary precautions measures to prevent getting infected and also to create awareness about HBV infection, among the public and other health care workers [1].

*Corresponding author: Onyeka Chukwudalu Ekwebene

Nnamdi Azikiwe University Teaching Hospital, Nnewi.

Copyright (C) 2021 Author(s) retain the copyright of this article. This article is published under the terms of the Creative Commons Attribution Liscense 4.0. 
Vaccination and use of personal protective equipment's are the two major weapons for the prevention of hepatitis B infection. Recombinant HB vaccine which is licensed for use is advised for all health care workers and clinical medical students [3].

More than 1 billion doses of hepatitis B vaccines have been given worldwide and it is considered one of the safest \& most effective vaccines ever made. Though common side effects may include; soreness, swelling and redness at injection site. The vaccine may not be recommended for those with documented history of adverse reaction to the vaccine [4].

HBV is hyper endemic in Nigeria and arguably the highest in Sub-Saharan Africa. This is coupled with the fact that it is highly transmittable at the initial stage of the infection even without clinical symptoms and signs [5].Amongst Clinical Medical Students /health care workers, zero prevalence is two or four times higher than that of the general population. They remain at high risk of acquiring HBV infection mainly through percutaneous or mucosal exposure to infected blood or body fluids [6].

As a result of subclinical course, the disease runs at the initial stage of infection most of the time, there is also the risk of transmitting infection to patients by the apparently healthy looking medical student. The widespread diffusion of HBV with its accompanying cost implication in prevention, management and treatment in a low - income country like Nigeria poses a heavy burden for government and health - care providers [5].

In a study in Pakistan in 2011, it was reported that the vaccination coverage of HBV among medical students was low in spite of the availability and accessibility of a cost-effective vaccine [7]. Another study showed that there are significant immunity gaps against all vaccine preventable diseases among healthcare students in Athens, Greece [8]. In 2015, a study by Okwesili et alrevealed a high prevalence of HBV infection among Biomedical Students in Sokoto, Nigeria [8].Hepatitis B, being an object of public health concern ought to be adequately known and properly handled by students training to be health personnel in various capacities first to preserve their own health and prevent undue medical expenses and also to curtail cross-transmission to one another or to patients in their care together with its legal implications.

The objective of the study was to determine the level awareness, accessibility and barriers to uptake of hepatitis B vaccine among under graduate clinical medical students in a tertiary institution in south east Nigeria.

\section{Material and methods}

\subsection{Study area}

The study area was Nnamdi Azikiwe University Teaching Hospital. It is a Federal hospital that trains medical students, paramedical Students, Nurses and Resident doctors. The hospital is located at Nnewichi Nnewi and the college of Health Sciences, Nnamdi Azikiwe the college and has somepre-clinical students (200-300level), who stay at Okofia and the clinical student $(400-600 \mathrm{~L})$ who stay within the hospital premises. The study population is the clinical medical students.

\subsection{Study design}

This study is a cross - sectional and descriptive study.

\subsection{Study tool}

Self-administered questionnaire was used.

\subsection{Study population}

This study was carried out among the clinical students of the Nnamdi Azikiwe University Teaching Hospital.

\subsection{Inclusion criteria}

All bona fide clinical students of the Faculty on Medicine, Nnamdi Azikiwe University was included.

\subsection{Exclusion criteria}

Post graduate, suspended or rusticated students of the faculty were excluded from the study. 


\subsection{Sample size determination}

Minimum sample size was determined using

Where:

$$
\begin{gathered}
\mathrm{Nf}=\mathrm{n} /(1+\mathrm{n} / \mathrm{N}) \\
\mathrm{n}=\frac{Z^{2} P Q}{d^{2}}
\end{gathered}
$$

$\mathrm{Nf}=$ sample size if population $<10,000$

$\mathrm{N}=$ estimated population size $=240$

$\mathrm{n}=$ minimum sample size

$\mathrm{Z}=$ standard normal deviation at $95 \%$ confidence level $=1.96$

$\mathrm{P}=$ estimated prevalence based on previous studies $=36 \%=0.36$

$\mathrm{Q}=\mathrm{I}-\mathrm{P}=0.64$

$\mathrm{d}=$ precision or degree of accuracy $=0.05$

$$
\mathrm{n}=\frac{(1.96)^{2} \times 0.36 \times 0.64}{0.05^{2}}=354
$$

$\mathrm{Nf}=354 /(1+[354 / 240]=178$

\subsection{Sampling method /technique}

The sampling method used was convenient sampling technique. Self-administered questionnaire was taken to each student and shared randomly to members present in the location at the sampling time.

\subsection{Data Collection/Tools}

Data were collected within 2 weeks interval. The questionnaire had four sections; informed consent, participant's demographics, information on Awareness of hepatitis B vaccine and accessibility towards hepatitis B vaccination. The participants' demographics assessed include age, gender, state of residence and geographical zones, ethnicity, religion, marital status and level.

\subsection{Statistical Analysis}

Analysis was performed using the Statistical Software Package SPSS version 20.0.Descriptive statistics (including means and standard deviations) were calculated for the numerical variables.

\subsection{Ethical consideration}

The entirety of the study with focus on the objective and techniques involved were explained clearly to each participant and an informed consent was obtained. The participants were assured of the confidentiality and anonymity of all information that will be supplied in the study.

The participants were also given the freedom to withdraw from the study at any point with an assurance that their decision would not affect my decision to render medical services to them in the future.

\section{Results}

The mean age of the respondents isFifty nine point zero percent (105) are males while $41.0 \%$ (73) are females. The Igbo respondents accounted for ninety six point one percent (172) of the respondents, 0.6\% (1) is Yoruba while others tribes accounted for three point four percent of the respondents. Ninety two point one percent (164) are married with all the respondents being Christians. Ninety eight point nine (176) percent are in medicine while 1.1\% (2) is in nursing department. Forty-two-point one percent are in 600level, 40.4\% (72) are in 400 level while seventeen-point four percent(75) are in 500 level. 


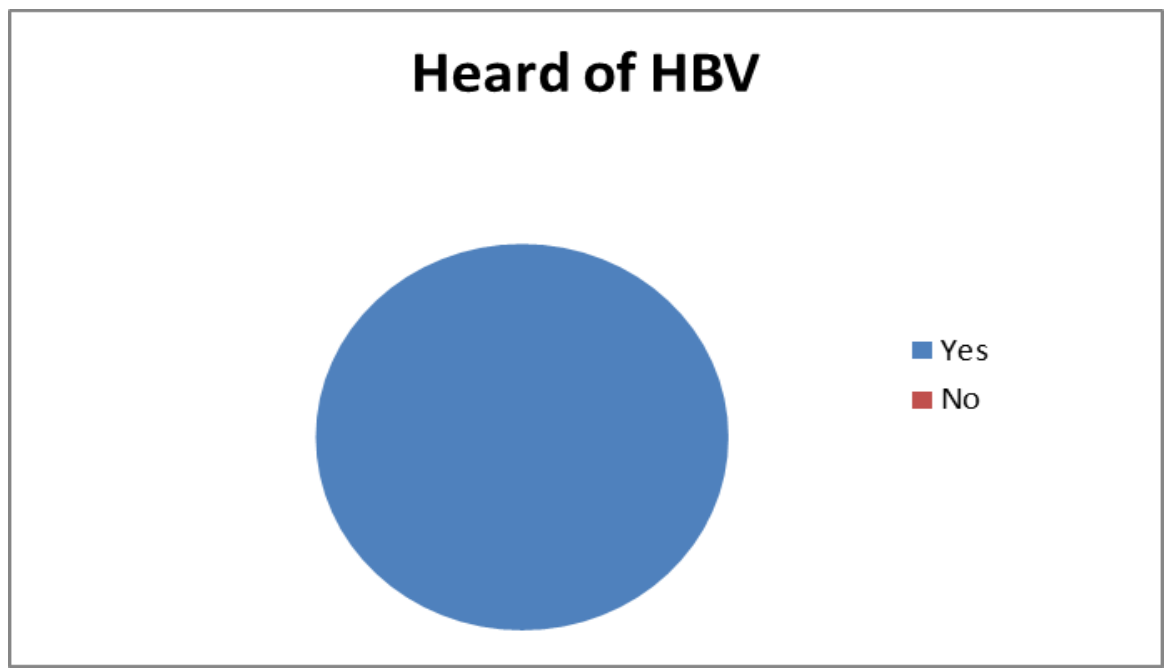

Figure 1Awareness of Hepatitis B virus vaccine

Table 1 Socio-demographic characteristics

\begin{tabular}{|c|c|c|}
\hline Socio-demographic characteristics & $\begin{array}{l}\text { Frequency } \\
\mathrm{N}=178\end{array}$ & $\begin{array}{l}\text { Percentage } \\
(\%)\end{array}$ \\
\hline \multicolumn{3}{|l|}{ Age } \\
\hline $15-20$ & 10 & 5.6 \\
\hline $21-25$ & 138 & 134.0 \\
\hline $26-30$ & 24 & 55.5 \\
\hline $31-35$ & 4 & 2.3 \\
\hline$>35$ & 2 & 1.2 \\
\hline \multicolumn{3}{|l|}{ Gender } \\
\hline Female & 105 & 59.0 \\
\hline Male & 73 & 41.0 \\
\hline \multicolumn{3}{|l|}{ Ethnicity } \\
\hline Yoruba & 1 & 0.6 \\
\hline Igbo & 172 & 96.1 \\
\hline Others & 6 & 3.4 \\
\hline \multicolumn{3}{|l|}{ Marital Status } \\
\hline Single & 164 & 92.1 \\
\hline Married & 14 & 7.9 \\
\hline \multicolumn{3}{|l|}{ Religion } \\
\hline Christian & 178 & 100 \\
\hline \multicolumn{3}{|l|}{ Department } \\
\hline Nursing & 2 & 1.1 \\
\hline Medicine & 176 & 98.9 \\
\hline \multicolumn{3}{|l|}{ Level } \\
\hline 400 & 72 & 40.4 \\
\hline 500 & 31 & 17.4 \\
\hline 600 & 75 & 42.1 \\
\hline
\end{tabular}

All the respondents haveheard of hepatitis B virus vaccine 
Table 2 Awareness of HBV

\begin{tabular}{|l|c|c|}
\hline & $\begin{array}{c}\text { Frequency } \\
\text { N=178 }\end{array}$ & $\begin{array}{c}\text { Percentage } \\
\text { (\%) }\end{array}$ \\
\hline Source of knowledge of HBV & 51 & 28.7 \\
\hline Family members & 81 & 45.5 \\
\hline Friends & 60 & 33.7 \\
\hline Television & 120 & 67.4 \\
\hline Book/Magazine & 100 & 56.2 \\
\hline Internet & 148 & 83.1 \\
\hline Health Staff & 154 & 86.5 \\
\hline Is HBV common in our environment & 5 & 2.8 \\
\hline Yes & 19 & 10.7 \\
\hline No & \multicolumn{2}{|l|}{} \\
\hline I don't know & 150 & 84.3 \\
\hline Symptoms of HBV & 118 & 66.3 \\
\hline Pain & 165 & 92.7 \\
\hline Vomiting & 146 & 82.0 \\
\hline Jaundice & 142 & 79.8 \\
\hline Live failure & 12 & 6.7 \\
\hline Live cancer & 63 & 35.4 \\
\hline Others & 144 & 80.9 \\
\hline Risk group for contracting HBV & 163 & 91.6 \\
\hline Infants & 158 & 88.8 \\
\hline Health Professionals & 9 & 5.1 \\
\hline Individuals with multiple sexual partners & \multicolumn{2}{|l|}{} \\
\hline Intravenous drug users & \multicolumn{2}{|l|}{} \\
\hline Others & \multicolumn{2}{|l|}{} \\
\hline & \multicolumn{2}{|l|}{} \\
\hline
\end{tabular}

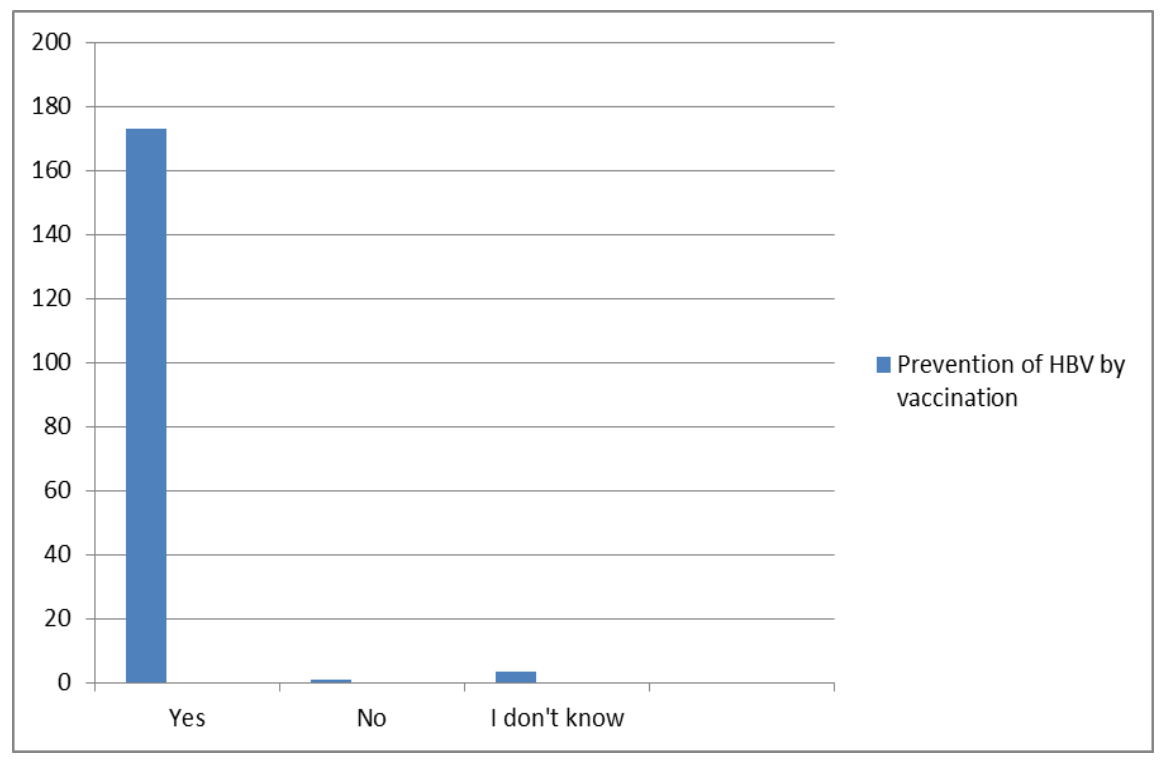

Figure 2Prevention of HBV by vaccination 
All the respondents are aware of hepatitis B virus vaccination with eighty three point one percent(148) having the source of their knowledge from a health staff, 67.4\%(120) has book/magazine and newspaper as the source of their knowledge while fifty six point two percent(100) knew from the internet. Eighty six point five percent (154) said that HBV is common in our environment, $10.7 \%$ are not aware if it's common or not while two point eight percent (5) said that it is not common. The commonest known symptom of HPV according to the respondents was jaundice (92.7\%). Abdominal pain accounted for $84.3 \%$. Those who said it was liver failure accounted for eighty two percent (146) while $79.8 \%$ (142) chose liver cancer. Individuals with multiple sexual partners (91.6\%) were the highest know risk group for contracting HBV. This is followed by intravenous drug usage which was eighty eight point eight while those said it was health professionals accounted for eighty point nine percent.

Ninety-seven-point two percent (173) agreed that HBV can be prevented by vaccination while $4 \%$ (2.2) are not sure if HBV vaccination can prevent it. Zero-point six percent (1) said that it cannot prevent it.

Table 3 Awareness of HBV vaccination

\begin{tabular}{|c|c|c|}
\hline & $\begin{array}{c}\text { Frequency } \\
\mathrm{N}=178\end{array}$ & $\begin{array}{c}\text { Percentage } \\
\text { (\%) }\end{array}$ \\
\hline \multicolumn{3}{|c|}{ Source of knowledge of vaccine prevention of HBV } \\
\hline Family members & 34 & 19.7 \\
\hline Friends & 57 & 32.9 \\
\hline Television/radio & 55 & 31.8 \\
\hline Book/Magazine/Newspaper & 93 & 53.8 \\
\hline Internet & 86 & 49.7 \\
\hline Health Staff & 145 & 83.8 \\
\hline Church & 15 & 8.7 \\
\hline \multicolumn{3}{|l|}{ Who to receive HBV vaccine } \\
\hline Infants & 91 & 51.1 \\
\hline Health professionals & 155 & 87.1 \\
\hline Health students & 150 & 84.3 \\
\hline Sexually active adults & 152 & 84.9 \\
\hline Others & 17 & 9.6 \\
\hline \multicolumn{3}{|c|}{ Knowledge of forms of vaccination } \\
\hline Yes & 127 & 71.3 \\
\hline No & 51 & 28.7 \\
\hline \multicolumn{3}{|c|}{ Those involved in HBV vaccination } \\
\hline Infants & 42 & 33.1 \\
\hline Health Professionals & 102 & 80.3 \\
\hline Students & 81 & 63.8 \\
\hline Young adults & 55 & 43.3 \\
\hline Others & 4 & 2.2 \\
\hline \multicolumn{3}{|c|}{ Number of doses required for full vaccine } \\
\hline 1 & 8 & 4.5 \\
\hline 2 & 7 & 3.9 \\
\hline 3 & 112 & 62.9 \\
\hline 4 & 11 & 6.2 \\
\hline I don't know & 40 & 22.5 \\
\hline
\end{tabular}

Ninety seven point two percent (173) agreed that HBV can be prevented by vaccination with $83.8 \%$ (1450 having health workers as their source of information. Those who knew from books/magazine and newspaper accounted for fifty three 
point eight percent (145) while 49.7\% got their knowledge from the internet. Only eight point seven percent (15) got their knowledge from church. Health care professionals $(87.1 \%)$ are the most eligible to receive HBV vaccination followed by health students and sexually active individuals accounting for $84.9 \%$ and $84.3 \%$ respectively. seventy one point three percent(127) are aware of the different forms of vaccination while $28.7 \%$ are not aware. Eighty point three percent(102) of the respondents chose health workers as those involved in HBV vaccination, Sixty three point eight percent(81) of those involved were students while the young adults accounted for $43.3 \%$ with majority(62.9\%0 receiving three doses while twenty two point five percent(40) do not know the number of doses received.

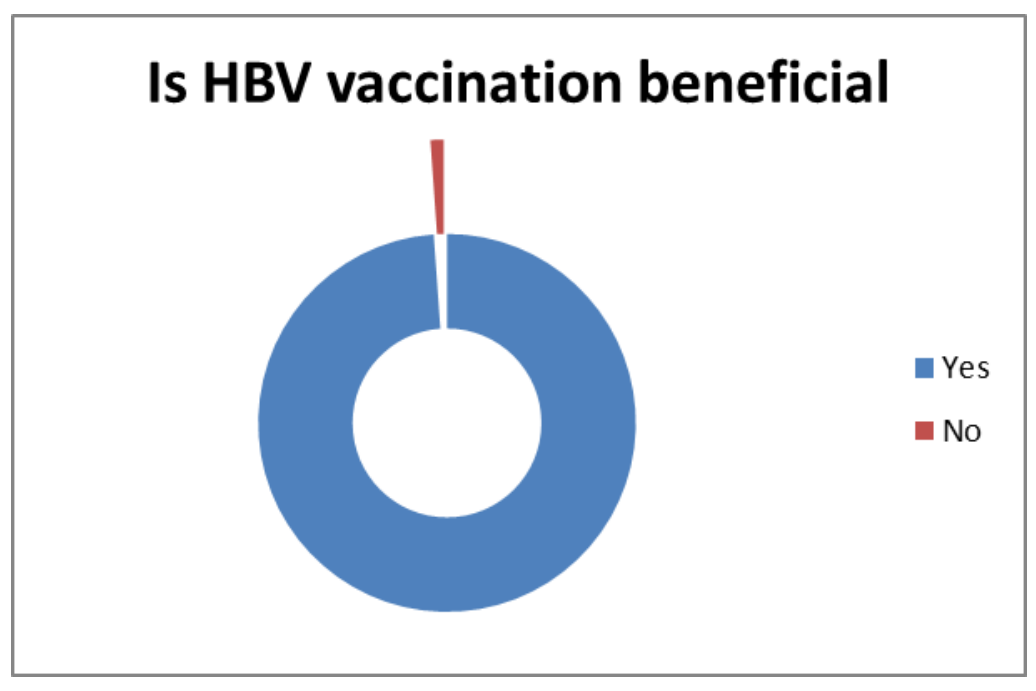

Figure 3 Assessment of HBV vaccination

Ninety-eight-point nine percent of the respondents (176) thinks that HPV vaccination is beneficial while 1.1\% (2) feel it is not

Ninety six point six percent (172) said that HBV vaccination is beneficial for the prevention of HBV, fifteen point two percent $t(27)$ said that it is recommended while $0.6 \%$ (10 do not know its benefit. Ninety seven point eight percent (174) will encourage others to get vaccinated with $96.6 \%$ (172) advocating for free HBV vaccine for all. Ninety three point three percent (166) said that HBV vaccine should be made compulsory for all health workers while 2.8\% (5) said no. Thos who have had HBV vaccination accounted for $27.5 \%$ of the respondents. Sixty four point two percent of those have not received HBV vaccination was because of high cost(74), Thirty three point one percent(40) did not receive it due to busy schedule while 10.7\% [13] lack awareness. Forty four point nine percent (22) respondents have received 3 doses, $28.6 \%$ (14) received one dose while twenty four point five percent (12) received two doses.Sixty-one-point two percent (30) had their first vaccination after sexual exposure, 20.4\% (10) had theirs voluntarily while $12.2 \%$ (6) received their first dose immediately after admission. Forty three point eight percent (14) did not receive HBV vaccine due to busy schedule, forty point six percent [13] did not receive due to unavailability while $25 \%$ (8) did not receive due to cost. Seventy nine point three percent (96) are willing to receive HBV vaccine while $19.8 \%(24)$ are not sure.

Table 4 Awareness of HBV Vaccination

\begin{tabular}{|l|c|c|}
\hline & $\begin{array}{c}\text { Frequency } \\
\text { N=178 }\end{array}$ & $\begin{array}{c}\text { Percentage } \\
\text { (\%) }\end{array}$ \\
\hline Benefits of HBV vaccination & 172 & 96.6 \\
\hline Prevention of HBV & 27 & 15.2 \\
\hline It is recommended & 1 & 0.6 \\
\hline I don't know & - & - \\
\hline Others & & 97.8 \\
\hline Encourage others to get vaccinated & 174 & 2.2 \\
\hline Yes & 4 & \\
\hline No & & \\
\hline
\end{tabular}




\begin{tabular}{|c|c|c|}
\hline \multicolumn{3}{|c|}{ Do you advocate for free or affordable HBV vaccination for all } \\
\hline Yes & 172 & 96.6 \\
\hline No & 6 & 3.4 \\
\hline \multicolumn{3}{|c|}{ Should HBV vaccine made compulsory for all health workers } \\
\hline Yes & 166 & 93.3 \\
\hline No & 5 & 2.8 \\
\hline I don't know & 7 & 3.9 \\
\hline \multicolumn{3}{|l|}{ Had HBV vaccination } \\
\hline Yes & 49 & 27.5 \\
\hline No & 121 & 68.0 \\
\hline I don't know & 8 & 4.5 \\
\hline \multicolumn{3}{|l|}{ First HBV vaccination } \\
\hline Immediately after admission & 6 & 12.2 \\
\hline After sexual exposure & 30 & 61.2 \\
\hline During clinical/laboratory exposure & 3 & 6.2 \\
\hline Voluntarily & 10 & 20.4 \\
\hline Others & - & - \\
\hline \multicolumn{3}{|l|}{ Reasons for not taking HBV vaccine } \\
\hline Lack of awareness & 13 & 10.7 \\
\hline Busy schedule & 40 & 33.1 \\
\hline Not Interested & 8 & 6.6 \\
\hline High cost & 74 & 61.2 \\
\hline Religious faith & - & - \\
\hline Others & 7 & 3.9 \\
\hline \multicolumn{3}{|l|}{ Number of HBV doses received } \\
\hline 1 & 14 & 28.6 \\
\hline 2 & 12 & 24.5 \\
\hline 3 & 22 & 44.9 \\
\hline 4 & 1 & 2.0 \\
\hline \multicolumn{3}{|c|}{ Reason for not receiving full vaccination } \\
\hline Busy schedule & 14 & 43.8 \\
\hline Cost & 8 & 25.0 \\
\hline Unavailability & 13 & 40.6 \\
\hline Lack of interest & 1 & 3.1 \\
\hline Others & 5 & 2.9 \\
\hline \multicolumn{3}{|c|}{ Willingness to receive vaccine against $\mathrm{HBV}$} \\
\hline Yes & 96 & 79.3 \\
\hline No & 1 & 0.8 \\
\hline I don't know & 24 & 19.8 \\
\hline
\end{tabular}

\section{Discussion}

From the results, knowledge of HBV as well as its symptoms and complication is high among undergraduate Clinical Students of college of health science Nnamdi Azikiwe University Nnewi Campus. This corresponds to study by Chingle MP et al in 2017, that awareness and perception of HBV infection are high among student of university of job, Nigeria [11]. 
There is high level of awareness of the prevalence of the infection and high level of knowledge of the individuals more at risk of contracting the infection with $86.5 \%$ (154) saying its common in our environment and $91.6 \%$ agreeing that individuals with multiple sexual pattern were the highest known risk group for contracting HBV About 148 (83.1\%) learnt it from a health staff, 120 (67.4\%) had books /magazine and newspaper as the source of their knowledge, while $100(56.2 \%)$ knew from the internet.

There was high level of knowledge of the ability of prevention of HBV Infection byvaccination with 173 (97.2\%) in agreement, while $4 \%$ aren't sure and $0.6 \%$ said that it cannot be prevented. $83.8 \%$ had health worker as their source of information, 53\% from books/magazines, $49.7 \%$ from the internet, only $8.7 \%$ from the church. The high level of knowledge of prevention by vaccination corresponds to the findings by Abdela A. el al in 2015 [10] and Okeke EN [9].There was also high level of knowledge of doses required for complete vaccination, 112 (62.9\%) 172 (96.6\%) said that HBC Vaccination is beneficial for the prevention of HBV, 27 (15.27\%) said it was recommended.

However there is low coverage of HBV Vaccination among Clinical Students with only 27.5\% of the respondents have been vaccination which correspond with some student in Europe and Saudi Arabia 74 (61.2\%) of the respondents citedhigh cost of vaccination as their reason for not yet receiving the vaccine which corresponds to the findings by Noubiap JJ et al in 2013 in Cameroon [13], 40 (33.1\%) cited busy schedule as their reason for not receiving vaccine familiar to the findings ofGhomraou FA et al [12] in 2016.

$13(10.7 \%)$ Sited lack of awareness as their reason for not getting vaccinated which correspond to the finding of Okeke E.N in 2008 [9] Forty four point two percent (22) respondent have received 3 doses, 28.6\% (14) received one dose while twenty four point five percent (12) received two doses. Sixty one point two percent (30) had their first vaccination after sexual exposure, $20.4 \%$ (10) had theirs voluntarily while $12.2 \%$ (6) received their first dose immediately after admission. Forty three point eight percent (13) did not receive due to vaccine due to busy schedule; forty point six percent (13) did not receive due to unavailability while $25 \%$ (8) did not receive due to cost. Seventy nine point three percent (96) are willing to receive HBV Vaccine while 19.8\% (24) are not sure.

\section{Conclusion}

There is a wide gap between the awareness of HBV Infection, importance of vaccination against it, the willingness to be vaccinated and the accessibility of the vaccine among clinical students of College of Health Science, Nnamdi Azikiwe University (CHS-NAU), Nnewi campus. This outcome however is different from the result obtained in other parts of world like Europe where there are good policies for childhood vaccination.

\section{Limitation of study}

- Unwillingness of participants to respond appropriately to the research or properly fill the questionnaires.

- High financial implication

- Non availability of a previous work on the same subject matter within the locality of my study area for comparative analysis.

\section{Recommendations}

- There should be increased awareness of HBV infection and importance of vaccination through the television, radio, and internet media which are among the easiest means of communication to the wider population.

- Policy for infant vaccination against HBV should be enacted and implemented.

- HBV Vaccination should be made mandatory for all health students upon admission or at least upon clinical or laboratory exposure.

- Vaccination should be scheduled for the students so as to prevent lack of vaccination due to a busy schedule.

- HBV vaccination should be made free or affordable and accessible for all.

\section{Compliance with ethical standards}

\section{Acknowledgments}

This research received no specific grant from any funding agency in the public, commercial, or not-for-profit sectors. 


\section{Disclosure of conflict of interest}

Authors declare that there is no competing interest.

\section{Statement of informed consent}

The guidelines on research involving the use of human subjects according to Helsinki declaration was adhered to. Online consent was obtained from participants. Participants were allowed to leave the survey at any time they desired. Confidentiality of information was assured, and the survey was anonymous.

\section{References}

[1] Mohan B, Samnathimmapa, Vihod Nambor, Rajew Arvindikshen. Hepatitis B Knowledge and Awareness Among Preclinical Year Medical Student. Avicenna J Med. 2019 Apr-Jun; 9(2): 43-47.

[2] Akanksha Ratthi, Vikas Kumar, Jitendra Majhi, Shalinin Jain, Panna Lal, Satyavior. Assessment Of Knowledge, Attitude And Practices Towards Prevention Of Hepatitis B Infection Among Medical Students In High Risk Settings Of A Newly Established Medical Institution. Journal Laboratory Physician 2018 Oct - Dec; 10(4): 374379.

[3] Kap of Hepatitis B Vaccination Among Health Workers at The Lagos State Accident and Emergency Centre TollGate, Alause, Lagos State 2014.

[4] Abiola Ao, Et Al. West African Journal Med 2013 Oct -Dec.

[5] Assessment of Hepatitis B Vaccination Status in Doctors of Jewish Hospital Lahire2014.

[6] Usmani Ra, Et Al. J. Ayuba Medical College Abbottabad. 2010aa June.

[7] Asif M, Raja W, Gorar Z. A Hepatitis B Vaccination Coverage in Medical Students at A Medical College Of Mirpur Khas. J Pak Med Assoc. 2011; 61(7): 680-682.

[8] Karageorgou K, Katerolos P. Efstathioum, Maltezou Hc Vaccination Coverage and Susceptibility Against VaccinePreventable Diseases Of Healthcare Students In Athens, Greece. Vaccine 2014; 32(39): 5083-5086.

[9] Adbela A, Woldu B, Haile K, Mattewose B. Deressa Assessment Of Knowledge, Attitude And Practices Toward Prevention Of Hepatitis B Virus Infection Among Students Of Medicine And Health Science In Northwest Ethiopia. Bmc Res Notes. 2016; 91(1): 410.

[10] Lohoues - Koualou Mj, Assi C, Nigue L, Biekre Ar, Onattra A, Kone S, Et Al. Hepatitis B: Cross Sectional Study Of Knowledge And Immunization Among Students At University Of Cocody, Ivory Coast. Rev Epidemiol Sante Publique. 2013; 61(5): 494-498.

[11] De Schryver A, Classen B, Meheus A, Van Spruidel M, Francons G. European Survey Of Hepatitis B Virus Policies For Healthcare Workers. Eur J Pub Health. 2011; 21(3): 338-343.

[12] Meslin Ym, Kibret Kt. Assessment Of Knowledge And Practice Towards Hepatitis B Among Medical And Health Science Students In Haramaya University, Ethiopia Plos One. 2013; 8(11): E79642.

[13] Noubiap Jj, Nansseu Jr, Kengre Kk, Tchoke Ns, Aguyungi Ia. Occupational Exposure To Blood, Hepatitis B Vaccine Knowledge And Uptake Among Medial Student In Cameroun. Bmc Medical Education. 2013; 13: 148. 